\title{
The complexity of team training: what we have learned from aviation and its applications to medicine
}

\author{
W R Hamman
}

Qual Saf Health Care 2004;13(Suppl 1):i72-i79. doi: 10.1136/qshc.2004.009910

Errors in health care that compromise patient safety are tied to latent failures in the structure and function of systems. Teams of people perform most care delivered today, yet training often remains focused on individual responsibilities. Training programmes for all healthcare workers need to increase the educational experience of working in interdisciplinary teams. The complexities of team training require a multifunctional (systems) approach, which crosses organisational divisions to allow communication, accountability, and creation and maintenance of interdisciplinary teams. This report identifies challenges for medical education in performing the research, identifying performance measurements, and modifying educational curricula for the advancement of interdisciplinary teams, based on the complexity of team training identified in commercial aviation.

Correspondence to: Captain W Hamman, Western Michigan University, $237 \mathrm{~N}$. Helmer Road, Battle Creek, MI 49015, USA; william. hamman@wmich.edu
T he importance of effective teamwork in health care is as critical to safety as it is in aviation. The failure of a healthcare team or flight crew may lead to a loss of life. Hackman ${ }^{1}$ notes that "it is the team, not the aircraft or the individual pilot, that is at the root of most accidents and incidents".

Traditionally, pilot training has concentrated mainly on the development of the technical skills and performance of the individual pilot. Indeed, both researchers and practitioners suggest that more emphasis should be placed on the performance of the crew as a team and on factors that affect crew coordination and teamwork, Hackman, Johnston, ${ }^{2}$ and Diehl ${ }^{3}$ further point out that ideally team skills and the principles of crew resource management (CRM) need to be introduced earlier in training, continuously reinforced, and reviewed during flight training. Similarly, Johnston" stresses that "if we want pilots to perform as a crew-as team memberswe should train them as a crew throughout".

The same situations exist in medicine. In health care, team errors encompass all settings in which care is delivered and engage all categories of healthcare workers. Errors in health care that compromise patient safety can be tied to latent failures embedded in the structure and function of systems. The Institute of Medicine's (IOM) report, To Err is Human, bluntly states, "most care delivered today is done by teams of people, yet training often remains focused on individual responsibilities, leaving practitioners inadequately prepared to enter complex settings. ...the "silos" created through training and organisation of care impede safety improvements". ${ }^{4}$

The complexities of team training require a multifunctional (systems) approach. This training moves beyond the training of individuals in an educational setting, to a dynamic team training system that crosses divisions within the organisation to allow communication, accountability, and the creation and maintenance of interdisciplinary teams. Commercial aviation has created a multifunctional system based on three principles that health care can emulate: transparency, standardisation, and team training. Health care should adopt a similar approach because "... in healthcare organisations, much of (the) learning is aimed at improving individuals - physicians learning to become better physicians, nurses learning to become better nurses - rather than learning how the system as a whole can improve" ${ }^{\prime \prime}$ Both fields require high levels of selfconfidence and decision making abilities. Most strikingly, within their respective fields, practitioners of both disciplines function largely in the absence of direct supervision; individual performance is seldom directly observed or monitored. Errors in both fields can have devastating effects. Over the last 30 years, commercial aviation has developed meaningful measures of individual, team (aircrew), and system performance. ${ }^{6}$ Aviation has been able to translate these measures into standardised best practices. By specific assignment of accountability, aviation system management assures adherence to these best practices. Although all three principles (transparency, standardisation, and team training) are critical for success of a dynamic healthcare education that crosses divisions within the healthcare system, this paper will primarily focus on the element of the team training process developed in the aviation community.

The focus of our discussion will be on the complexity of effective team training identified in aviation. Team training:

- Requires management to address the challenge for crosscultural training.

Abbreviations: AAIB, Air Accidents Investigation Branch; AQP, Advanced Qualification Program; ATC, air traffic control; CRM, crew resource management; IOM, Institute of Medicine; NASA, National Aeronautics and Space Administration; PAC, pulmonary artery catheter; RHC right heart catheterisation; SOP, standard operating procedure; SPO, supporting proficiency objective; TPO, terminal proficiency objective 
- Is not a one time immunisation given in isolation to a professional in a 2 day seminar. Instead, it is long term commitment to a training plan, integrated throughout the career of the professional.

- Requires a curriculum designed by a task analysis, with specific team goals established for each phase of a professional's career.

- Requires interdisciplinary simulations that incorporate both technical and interdisciplinary team skills in a dynamic scenario design.

Two systems developed to address these issues are the Advanced Qualification Program (AQP) and the simulation scenario design process. These design systems will be discussed and their application to medicine identified.

Human factors and CRM team training was slow to gain acceptance in the aviation community. In medicine, the same situations exist, as team training has not advanced significantly in health care. The main reason is a cultural paradox, which is comprised of clusters of subparadoxes. I will focus on two of the predominate paradoxes that inhibit effective team training.

\section{THE MANAGEMENT CHALLENGE}

Most airlines and healthcare organisations require their personnel to be exposed to human factors and team training, thus tacitly acknowledging that these issues are important. The first paradox is most organisations operate in a profit motivated environment, which often lead to decisions being made that are antithetical to the principles of human factors and team training. For example, it is well established that human factors and team dynamics are fundamentally approaches to life and work, yet most organisations provide one short exposure to these issues and expect real change to occur-that is, there is an expectation that lifelong habits can be changed by an intervention lasting a day or two. This paradox is really identifying the fact that a short 1 or 2 day course to individuals is inexpensive and easy to administer. Although individuals trained in team issues may understand the benefits of team training, the cultural elements remain in the workplace, insufficient identification, integration, and simulation practice of team skills are available, and no recurrent training/assessment will have been provided. The good results are simply diluted by time and inertia.

To address these challenges, fundamental human factor instructional requirements must be combined with interdisciplinary team training, and integrated throughout the education of healthcare personnel. This training is developed by a curriculum designed from a task analysis of the team training requirements. There should be two distinct components for this training. Team training for initial instruction and introduction to the concepts of team performance and continuing ongoing education of healthcare workers. This training becomes an integral component of the assessment criteria for the healthcare personnel, and includes interdisciplinary simulations that incorporate both technical and interpersonal skills designed into dynamic scenario presentations. This requires a tremendous commitment from management. This commitment can be facilitated by the education of the senior leadership in the healthcare organisation about the need for collaborative, team oriented behaviour that forwards the goal of improved patient care and safety. On of the most effective educational tools in aviation is the flow of performance data and material on all aspects of how team functioning or lack thereof can affect an organisation. This may included a flow of material to operational personnel on the ethical and economic issues involved in running the organisation profitably; reports of operational problems attributed to a breakdown in teams; and reports of economic problems caused by a breakdown in teams. This is obviously a long term project, as it will take time and trend analysis to demonstrate the impact of team training on the reduction of lost lives and the economic performance, but the improvements are there to be seen when the links are established between effective team training and the reduction of error, improved patient care, and regulatory compliance.

The second paradox regarding how we train teams is the challenge introduced when several different disciplines must come together as a functional team. Because nurses and physicians are trained separately, it is difficult for individual clinicians to capitalise on the capabilities and recognise the limits of the other profession. Fulginiti states: "it is the clear understanding of other types of practitioners, together with the ability to combine forces that can best ensure the desired outcome: a patient's optimal health". ${ }^{7}$ Lacking this knowledge, clinicians function in proximity and parallel to each other, in contrast to true team approaches that allow roles to safely intersect in the provision of patient care: "In an effective interdisciplinary team, members come to trust on another's judgments and attend to one another's safety concerns". ${ }^{4}$ Achieving safe patient care that results from the interaction of different disciplines is difficult to accomplish without adequate understanding of the contributions of different providers and mechanisms that enhance interaction among them. Isolated training prevents nurses and physicians from "work(ing) together to share authority and collaborate in problem solving". ${ }^{4}$ Solving problems is a constant in aviation and healthcare environments. Effective, lasting solutions typically require various disciplines using systems approaches. Interdisciplinary teams can bring different perspectives to evaluating vulnerabilities in care systems, such as new technologies, alterations in processes and procedures, or significant changes occurring within an organisation.

\section{IDENTIFYING THE NEED FOR CROSSCULTURAL TEAMS IN AVIATION}

In aviation, we have learned the need to train across disciplines. On 9 March 1989, an Air Ontario Fokker F-27 was getting ready for takeoff from a small airport in Northern Ontario. There were two pilots, two flight attendants and 64 passengers on board, including two commercial pilots travelling with their families. Takeoff was delayed as the tower waited for a small private aircraft to land; it was lost in the spring snowstorm. While the jet waited for takeoff clearance, several passengers noticed an accumulation of snow on the wings. One of them brought it to the attention of the in charge flight attendant, who assured them that there was nothing to worry about. The flight attendants did not think it appropriate to say anything to the operating pilots. The aircraft took off, then crashed in a wooded area just beyond the runway because of the snow on the wings. There were 24 fatalities, including the two operating pilots and one flight attendant. When asked about this during the course of the investigation and subsequent public inquiry, the one surviving crew member, the other flight attendant, stated that she did not feel it was her job to inform the pilots of a potential problem; she had never been trained to question an area that in her mind was clearly a pilot responsibility.

Another incident involved a British Midlands 737, which crashed near Kegworth in Leicestershire. To quote from the Air Accidents Investigation Branch's aircraft accident report ${ }^{8}$ : "Although the cabin crew immediately became aware of heavy vibration at the onset of the emergency and three aft cabin crew saw flames emanating from the No. l engine, this information was not communicated to the pilots". 
Many more incident/accidents can be attributed to the fundamental breakdown in teams across disciplines in aviation. These comments are not intended to apportion blame to any of the crewmembers involved in these accidents. What was identified was that their training and procedures did not give them the tools to operate in any other way. A study conducted at the National Aeronautics and Space Administration (NASA) Ames Research Center in California' identified the following five factors as influencing the differences between the two disciplines, which then contribute to the problem.

- Historical background: origins of the two jobs and the influence on today's personal attributes and attitudes.

- Physical separation: a serious lack of awareness of each other's duties, responsibilities and problems, influenced by a lack of physical proximity.

- Psychological isolation: personality differences, misunderstanding of motivations.

- Regulatory factors: confusion over procedures and licensing issues.

- Organisational factors: administrative segregation, differences in training and scheduling.

In health care, these same factors, with some variation, exist to warrant breaking down the "silos" (barriers) by interdisciplinary team training. Physicians have traditionally dominated care. Frequently, those who exercise power and sole decision making authority in a hierarchy will not easily give up their position, but will pursue policies that continue their dominance in the organisation. ${ }^{10}$ This traditional model of healthcare delivery no longer meets the needs of delivery systems or patients, as the provision of all health care has become too complex to rest in the hands of a single professional. Physicians and nurses, as students and practitioners, occupy the same physical space in caring for a patient; however, they frequently communicate ineffectively and indirectly while managing conflicting goals. Developing effective, interdisciplinary teams is a tool to align delivery systems to better meet patient needs and improve the quality of care.

\section{TEAM TRAINING REQUIRES A CURRICULUM DESIGNED BY A TASK ANALYSIS}

From the days of the Wright brothers until the 1970s, formal training for pilots focused only on the technical (stick and rudder) components of flight. This situation changed dramatically after 1978, when NASA researched the causes of commercial air crashes. NASA drew the then astonishing conclusion that the majority of disasters resulted not from pilot's lack of technical skill or mechanical failure, but from error associated with breakdowns in communication, leadership, and teamwork. ${ }^{11}$ Industry response to these data was to initiate a new type of training, cockpit resource management (CRM), dealing with the interpersonal, team aspects of flying in a multiperson crew. As the concept matured, the acronym remained, but the name changed to crew resource management to reflect the fact that safety critical interactions extend beyond the confines of the flight deck. ${ }^{12}$

The road to training specific team skills in addition to the technical components of flight training was a difficult one. For several years, no specific behaviours of team effectiveness were identified with enough detail to allow true integration and training. Although the high level topics of team effectiveness (communication, leadership, workload management) had been identified, the elements of these topics had not. Additionally, the system of how a pilot was trained allowed no room to include team training because there was a conflict between the regulatory requirements for pilot
Conclusions for management

Effective team training is not a one time immunisation given in isolation to a healthcare professional in a 2 day seminar. Instead, it is long term commitment to a training plan, integrated throughout the career of the healthcare professional, which will include the following attributes:

- A curriculum designed by a task analysis with specific goals establishes for each phase of a healthcare professional's career.

- Interdisciplinary simulations that incorporate both technical and interdisciplinary team skills in a dynamic scenario design.

- An organisation that supports, participates, and provides the resources required to allow this training be successful.

certification, which was technically based, and team training, which was not required. Finally, there was a major concern expressed by the pilot groups dealing with the issue of evaluation on team performance. How could there be evaluation risk to the pilots based on ambiguous team skills that have been ineffectively trained? Is team training going to take away my authority as captain and ultimate decision maker?

In the late 1980s, as human factors were contributing to $70 \%$ of the aircraft accidents, the industry came together to address the need for training team skills in conjunction with the technical requirements to safely operate a complex transport category aircraft in a complex operational environment. It was obvious from the statistics that the way pilots had been trained for the past 40 years was no longer sufficient in the modern environment. The result of this collaborative effort was the Advanced Qualification Program (AQP). The AQP curriculum identified specific team skills that enhance safety through effective use of all available resources: human, hardware, and information. The AQP process achieves a greater degree of integration for the team skills, while the AQP team training and practice increases awareness of human and system error, and provides techniques and skills that will minimise their effects. This is accomplished through awareness of crewmember attitudes and behaviour, and the use of practical management skills. The Advanced Qualification Program develops training by the categories of:

- Topic or TPO—Subtopic or SPO—team skill—observable behaviour.

- Topic or terminal proficiency objective (TPO) is a high level team concept of primary importance. An example of a topic would be "Communication".

- Sub-topic or supporting proficiency objective (SPO) are key elements of the Topic (TPO). An example of a subtopic or SPO under "Communication" would be "Inquiry".

- Team skill is the ability of a person to apply specific knowledge across various conditions. SPOs are composed of numerous team skills. An example of a skill under "Inquiry" would be "Seek answers actively".

- Observable behaviour is a specific action employing a skill in a given condition. An example of an observable behaviour under "Seek answers actively" would be "First officer questions if there is adequate fuel to reach destination".

- Attitudes are complex human states that affect behaviour towards people, things, and events. 
- Communication $\rightarrow$ inquiry: seeks answers actively $\rightarrow$ first officer questions if there is adequate fuel to reach destination.

All team topics work together to affect the overall safety of a flight. In practice, team skills are a complex, continuous and dynamic process that leads to an effective outcome. Examples of a cluster of team skills are as follows.

\section{Communications processes and decision behaviour}

This topic includes internal and external influences on interpersonal communications. External factors include communication barriers such as rank, age, gender, and organisational culture, including inadequate standard operating procedures (SOPs). Internal factors include speaking, listening, and decision making skills, conflict resolution techniques, and the use of appropriate assertiveness and advocacy. The importance of clear and unambiguous communication must be stressed in all training activities involving pilots, flight attendants, and aircraft dispatchers. The greater the concern in flight related matters, the greater the need for clear communication. More specific subtopics include the following.

- Briefings: training in addressing both operational and interpersonal issues, and training in establishing and maintaining open communications. Briefings should reaffirm established SOPs.

- Inquiry/advocacy/assertion: training in the potential benefits of crewmembers advocating the course of action that they feel is best, even though it may involve conflict with others.

- Crew selfcritique (decisions and actions): illustrating the value of review, feedback, and critique, focusing on the process and the people involved. One of the best techniques for reinforcing effective human factors practices is careful debriefing of activities, highlighting the processes that were followed. Additionally, it is essential that each crewmember be able to recognise good and bad communications, and effective and ineffective team behaviour.

- Conflict resolution: demonstrating effective techniques of resolving disagreements among crewmembers in interpreting information or in proposing courses of action; and techniques for maintaining open communication while dealing with conflict.

- Communication and decision making: demonstrating effective techniques of seeking and evaluating information; and showing the influence of biases and other cognitive factors on decision quality. There are benefits in providing crews with operational models of this group decision process. Crews may refer to these models to make good choices in situations when information is incomplete or contradictory.

\section{Team building and maintenance}

This topic includes interpersonal relationships and practices. Effective leadership/followership and interpersonal relationships are key concepts to be stressed. Curricula can also include recognising and dealing with diverse personalities and operating styles. Subtopics include:

- Leadership/followership/concern for task: showing the benefits of the practice of effective leadership through coordinating activities and maintaining proper balance between respecting authority and practising assertiveness; and staying centred on the goals of safe and efficient operations.
- Interpersonal relationships/group climate: demonstrating the usefulness of showing sensitivity to other crewmembers' personalities and styles; emphasising the value of maintaining a friendly, relaxed, and supportive, yet task oriented tone in the cockpit and aircraft cabin; and the importance of recognising symptoms of fatigue and stress, and taking appropriate action.

- Workload management and situational awareness: stressing the importance of maintaining awareness of the operational environment and anticipating contingencies. Instruction may address practices (for example, vigilance, planning and time management, prioritising tasks, and avoiding distractions) that result in higher levels of situational awareness. The following operational practices may be included: (a) preparation/planning/vigilance: issues include methods to improve monitoring and accomplishing required tasks, asking for and responding to new information, and preparing in advance for required activities; and $(b)$ workload distribution/distraction avoidance: issues involve proper allocation of tasks to individuals, avoidance of work overloads in self and in others, prioritisation of tasks during periods of high workload, and preventing nonessential factors from distracting attention from adherence to SOPs, particularly those relating to critical tasks.

- Individual factors/stress reduction: training in this area may include describing and demonstrating individual characteristics that can influence crew effectiveness. Research has shown that many crewmembers are unfamiliar with the negative effects of stress and fatigue on individual cognitive functions and team performance. Training may include a review of scientific evidence on fatigue and stress and their effects on performance. The content may include specific effects of fatigue and stress in potential emergency situations. The effects of personal and interpersonal problems and the increased importance of effective interpersonal communications under stressful conditions may also be addressed. Training may also include familiarisation with various countermeasures for coping with stressors. Additional curriculum topics may include examination of personality and motivation characteristics, selfassessment of personal style, and identifying cognitive factors that influence perception and decision making.

- For each of the high level topics there are specific skills and observable behaviours linked to allow specific training and practice of these topics. To reiterate, the principles of AQP are: (a) systematically developed; $(b)$ proficiency based; and (c) mission oriented; and $(d)$ the training emphasis is on team performance; $(e)$ team skills are integrated with technical performance; $(f)$ team simulation scenario training is required; and $(g)$ the programme is validated by data.

These concepts have enhanced the advancement of team training in aviation because it allows training of the team skills along with the technical skill requirements.

\section{TEAM TRAINING REQUIRES INTERDISCIPLINARY SIMULATIONS}

Another complexity of team training is developing the appropriate environment for skill acquisition and practice. Traditional lecturing is known to be very ineffective. Team skills need to be practised in the operational environment; this is where dynamic simulations presenting operational scenarios are very effective. However, it took years of work to create the effective use of simulation. Although operational team scenarios had been developed for aviation simulation, over the years it was discovered their effectiveness was not 
significant. The reasons for this were that the initial team scenarios were not systematically developed or implemented, they did not have defined goals or outcomes, they conflicted with the technical training, and there was no feedback of the relevance or significance of the team scenarios in the operational environment. Additionally, the importance of the team scenarios was mitigated by the fact that the crews were aware that their success in the programme was based only on their technical proficiency; there was no requirement for assessment or demonstration of team proficiency. This was changed under AQP, which required both assessment of crew performance and of technical proficiency. To move toward this requirement of team performance, the industry, in collaboration with the regulatory agencies, developed the concept of the event set for team scenario training and assessment. Original simulator team training encompassed the entire scenario from start to finish (fig 1).

In the new training environment under AQP, the primary unit of both simulator scenario model design and assessment is the scenario event set, a group of related events that are part of the scenario and are inserted into a simulator session for specific objectives (fig 2 ). ${ }^{13}$

The scenario event set is a refinement of the AQP concept of event, and, like that concept, is an integral part of the assessment. The event set is made up of one or more events, including an event trigger, distracters, and supporting events. The event trigger is the condition or conditions under which the event is fully activated. The distracters are conditions inserted within the event set timeframe that are designed to divert the team's attention from other events that are occurring or about to occur. Finally, supporting events are other events taking place within the event set that are designed to further the training objectives. The following is an example of a training event set taken from a aviation simulation scenario.

\section{Event set 4 (aviation): engine failure at cruise}

Event set number 4 will begin during the en route phase of flight in the area of Lincoln, Nebraska. The event trigger will be an illumination of an engine overheat light. The aircraft condition after the checklist is complete will be the engine may be operated slightly above idle thrust. At any higher thrust setting the overheat light will illuminate.

The event distractors will include: $(a)$ the single engine performance and need to descend to lower altitude and $(b)$ ambiguity in the ability to operate the engine at idle thrust versus engine shutdown. The supporting events will include the increased communication demands to contact the airline company, air traffic control (ATC), and the cabin crew concerning the current problem with the engine and the ramifications.

\section{Team training criteria \\ Command}

There are several issues the crew must address and the captain will demonstrate his/her authority as captain. As an example, the crew must declare an emergency after the engine failure, and must make a decision to proceed to

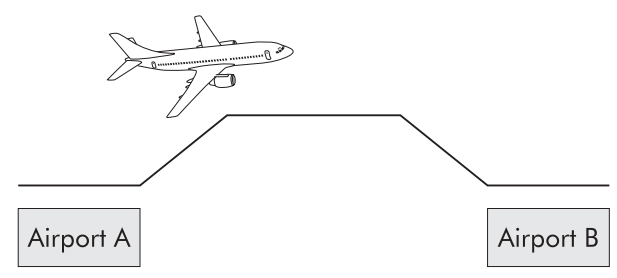

Figure 1 Representation of entire simulation training scenario (original team training) from takeoff to landing.

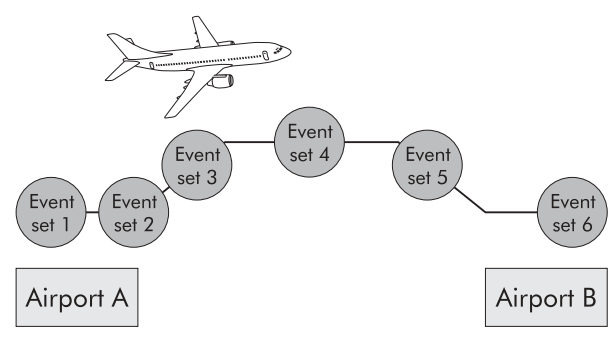

Figure 2 Representation of simulation training scenario from takeoff to landing (team/technical assessment by event set design process). This is an AQP designed process used to identify event sets with specific team and technical performance factors.

another airport with the best conditions. The captain should solicit and acknowledge crewmembers' concerns about the decision of the best airport towards which to proceed. A good crew climate will be required for the open exchange of information to facilitate processing of all the information of this event set.

\section{Leadership}

Problem solving, decision making, and communication are critical for the successful outcome of this event set. The flight crew must not only solve the problem of the engine failure, but must also make decisions about the alternative airport, continued single engine operations, and communication to the flight attendant crew concerning these issues.

\section{Workload management}

Effectively prioritising the sequencing of the tasks faced by the crew is the other critical factor of this event set; for example, the crew must prioritise the communication issues with ATC, the company, and the flight attendants regarding the flight issue of the single engine operation.

\section{Situational awareness}

The crew must assess the environmental conditions affecting the conduct of flight such as the relationship of the aircraft to terrain, weather, and ATC, and the spatial orientation of the aeroplane itself. The crew must avoid potential distractions and preoccupations such as programming of autoflight systems and performing irregularities, and the emergency checklist.

\section{Technical training criteria}

Technical training criteria include:

- Definition of the engine problem

- Engine shutdown checklist and SOP if the crew decides to shut the engine down

- Knowledge of federal air regulations concerning single engine operation and their application to this situation. If an engine fails in flight, diversion is required to the nearest suitable airport, in point of time, at which a safe landing can be made. Diversion to the nearest suitable airport is considered by United Airlines to be the diversion alternative that, in the captain's judgement and considering all applicable factors, will result in the highest level of safety. These factors include: (a) aeroplane performance; (b) flying time to the alternative airport; (c) en route weather, terrain, and obstructions; $(d)$ en route and terminal navigation aids; (e) terminal weather, facilities, and number/type of approaches; and $(f)$ number, length, and condition of runways, plus pilot familiarity.

- The pilot flying must demonstrate proficient single engine flying skills. 
Thus, in aviation, a scenario from A to B is broken into 6-7 event sets. These event sets provide a specific focus for integrating technical and team skills for training or assessment in an operational environment, and create the focus for data collection of technical/team performance (fig 3).

\section{IMPLICATIONS FOR MEDICINE}

Medicine could also benefit from the integration of human factor and technical skill performance that AQP methodology has developed. Seldom, it seems, is an optimal team atmosphere established in medicine. There are frequent problems with informing other team members of work overload or of developing patient problems. Formal leadership is infrequently established for the procedure, although in discussions, assumptions were aired by attending physicians, nurses, and anaesthesiologists that they were de facto leaders. One result of the failure to establish leadership and to plan for alternative courses of action in the event of patient difficulties was frequent conflict. Anecdotally, most physician and nurses can readily recount examples both of optimum teamwork and of equally impressive conflict from their own experiences. The advanced medical simulator would be a wonderful tool for training the human factors team skills that are required by medical teams to perform at optimum levels of performance. This crosscultural training would bring together the individual technical skills of different medical disciplines to work together and build medical team concepts. The end level concept would be a crosscultural understanding of medical teams and how each group can be in a symbiotic relationship with each other to demonstrate a greater level of performance as a team. An example of this would be as follows.

One of the most common invasive vascular procedures involves the use of a pulmonary artery catheter (PAC) to perform right heart catheterisation (RHC). Currently, more than 1 million PACs are used annually in the USA in a variety of clinical and research settings. ${ }^{14}$ Residents with little

\section{The simulator scenario design process}

- The first step is to identify the primary team topics and associated subtopics linked to performance markers, and to integrate them with the primary technical training and performance objectives.

- The second step is to identify incidents through a search of incident data identified by the safety groups.

- The third step is to specify simulation scenario objectives, related TPOs, primary and secondary team categories, and observable crew behaviours for each scenario event set. This includes the translation of incidents and situations into scenario event sets and the administration of the simulation scenario validation instrument.

- The fourth step is to represent the simulation scenario showing the event sets, event trigger, and the related team/technical topics, to test the simulation scenario using at least two different groups of experts, to administer the same simulation validation instrument to the experts and instructor(s) that test the scenario, and to make required modifications to the scenario.

- The fifth step is to develop final representation of the simulation scenario for instructors/evaluators with emphasis on event sets, and to implement the training curriculum for the instructors/evaluators.

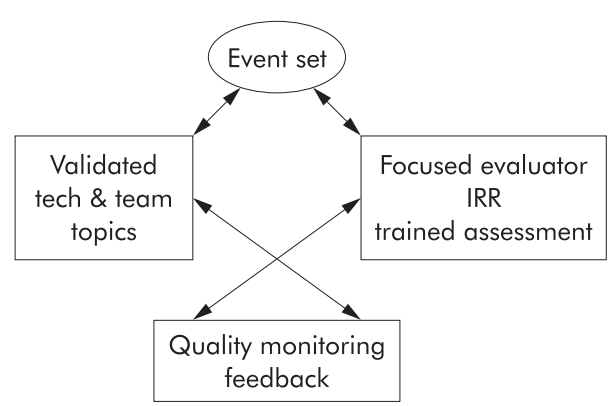

Figure 3 The core focus for simulation training is the event set. The event set is the focus of scenario based evaluations.

experience and under minimal supervision often perform insertion of the PAC. Adverse outcomes related to the use of the PAC include complications of insertion (arrhythmia, vascular injury, perforation of cardiac chambers), and complications related to misinterpretation or misuse of the haemodynamic data derived from the PAC. It has been clearly demonstrated that the skill level and knowledge base even of highly trained individuals such as critical care nurses or physicians is less than desirable. ${ }^{15-18}$ Thus, the identified incident is complications during PAC induced by poorly trained critical care teams.

An analysis of human factors in aviation will naturally centre on the behaviour of the aircrew and the operational particulars of any one flight. In medicine, such an analysis goes far beyond such narrow constraints. By its very nature, medical practice is much less proceduralised than flying an aircraft. Most work settings in medicine do not benefit from the obvious safeguard of having two individuals of similar (or virtually identical) training sharing responsibility for one task. Work groups are more heterogeneous, with representatives from many fields (for example, invasive cardiologists, cardiovascular trainees, nurses, cardiovascular technicians and anaesthesiologists comprising a team in the cardiac catheterisation laboratory) interacting, each with their own sets of skills and areas of expertise. Furthermore, the composition of such teams is not always static but changes during the procedure. Physicians come and go throughout the day, while nursing shifts change at regular intervals.

So, what is the nature of the human factor problems in medicine, and more specifically, in the practice of complex invasive procedures? This is not a simple question. In general, it is best to frame an understanding of the problems on three levels. At the level of the individual practitioner, there are factors that can impair individual performance and increase the likelihood of making mistakes. At the interpersonal or team level, there are also factors that may impair performance both in and out of a complex procedure. These factors may involve cooperation, communication, leadership, decision making, and other aspects of teamwork typical of the problems addressed in aviation CRM programmes. The third level is that of the medical system, where it is possible to identify numerous factors that impede safe healthcare delivery and pose a threat to patients.

There are many solutions to this problem, including the development of scenario based simulation team training to facilitate change. The sequence includes:

- Identification of individual and team training objectives for the RHC event.

- Translation of training objectives into representative scenario events that provide opportunities for trainees to demonstrate learning and competencies related to the training objectives. 
- Development of performance criteria that are incorporated into event based performance measures.

- Development of procedures that enable instructors (or systems) to observe and provide feedback on team processes and outcomes.

- Linking performance data to a historical performance database (this allows individual and team strengths and weaknesses to be diagnosed, and serves to focus future training events).

- Update master task lists based on empirically identified training needs.

The final dimension to the above process is the assignment of success criteria to the event sets as developed above. This is critical because it will be used for the objectives of the event set, and the evaluation of performance in the assessment of simulation effectiveness. Additionally, this information will be used as the baseline for data collection for identification of focus areas for ongoing training.

Assessment of the event set team should be viewed as an expansion of the assessment of technical proficiency of a specific procedure. Under this system, when a procedure is undertaken, the team is expected to perform within a given set of performance criteria. These criteria are normally based on the outcome of the procedure. Likewise, in the event set, assessment should be based on the outcome of each event set in the simulator scenario. The final assessment for the entire simulator scenario is based on the summation of the performance of the individual event sets. For example, in a medical team training scenario for PAC/RHC, the following is an sample event set. A full scenario would be made up of several event sets (fig 4).

\section{Event set $\mathbf{4}$ (medicine): induced bradycardia}

The event set scenario is implantation of a PAC. During right heart catheterisation (RHC) the patient developssignificant bradycardia, requiring medical intervention (the event trigger) The event distractors will include: additional workload, which includes a difficult catheter insertion causing task overload of the physician. The supporting events will include: the supporting physiological presentation of difficult anatomy, vital signs, and patient history to support scenario.

\section{Team training criteria}

Situational awareness

The medical team must have discussed issue before it could become a problem, and should request medical intervention for bradycardia prior to significant risk to patient.

\section{Leadership}

Problem solving, decision making and communication are critical for the successful outcome of this event set. The physician and team must not only solve the problem of the bradycardia but they must also make decisions about continuing the procedure and critical communication to entire team.

\section{Workload management}

Effectively prioritising the sequencing of the tasked faced by the team is the other critical factor of this event set. The physician must set clear priorities for tasks and their order.

\section{Technical training criteria}

The technical training criteria will be defined by the protocol for the procedure as defined in the cardiac care standards of the institution.

\section{CONCLUSIONS}

The core goal is to create a scientifically based, rigorous, multidisciplinary training curriculum using simulation as a

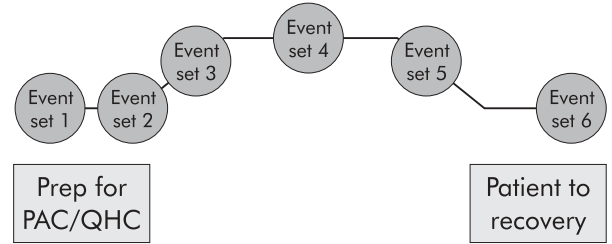

Figure 4 Representation of simulation training for a cardiac procedure in the event set design (team/technical assessment).

core tool for human factor team training, with performance measures to address specific, important clinical and patient safety needs.

Senior leadership in organisations, including clinical leaders of both nursing and medicine, should understand that a majority of the assigned human factor skills to the event sets are collaborative, team oriented behaviour that forwards the goal of improved patient safety. Collaboration is defined as a "joint communicating and decision-making process with the expressed goal of satisfying the... needs of the patient while respecting the unique qualities and abilities of each professional" ${ }^{\prime 1}{ }^{19}$ The leadership must understand that developing effective, interdisciplinary teams is a tool to align delivery systems to better meet patient needs and improve the quality of care.

In summary, in aviation we have learned that team training is a wonderful effective tool to improve operational performance. However, it is a very complex process to transfer to behavioural change of individuals and improved dynamics of teams. The results of this simulation training must create the foundation for policy, procedures, and practices that cross divisions within the healthcare system to allow communication, accountability, and the creation and maintenance of interdisciplinary teams. Most importantly, we have learned in aviation that at least $70 \%$ of the airline accidents and incidents over the past 20 years can be attributed to inadequacies in skills such as those related to crew coordination, workload management, and decision making. In these accidents and incidences, individual technical proficiency was not the primary factor (fig 5).

Aviation could not ignore the importance of the human element in our crew performance issues. These conclusions were identified by the dramatic loss of aircraft and needless loss of thousands of lives. In medicine, the accidents are not as dramatic as in aviation, but the loss of life is just as significantn. Over the years, thousands of deaths have been the result of human error. The IOM asserts, "although almost all accidents result from human error,...errors are usually

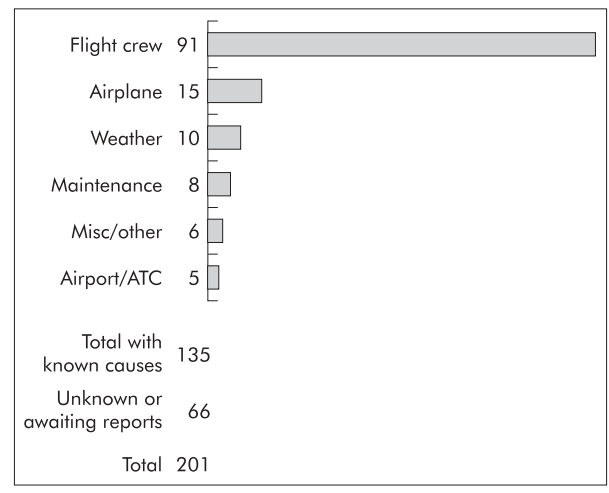

Figure 5 Statistical analysis of commercial jet accidents for the years 1990 to 1999 by primary cause. Information provided by Boeing Aircraft Corporation, 1990 Statistical Summary, June 2000, Rev A. 


\section{Key messages}

- Team training skills must be identified by task analysis, have identified TPOs, SPOs, skills, and behavioural markers of performance.

- From the first day of training, team skills are integrated into the curriculum lesson plans and supported by curriculum design.

- Team training skills must share equal importance with the technical skill requirements.

- The curriculum must be designed to support crosscultural training.

- The curriculum must integrate carefully designed simulation that is based on scientific models of team training generated from performance data from the environment.

- The team training elements must be integrated into the event set design with defined criteria for successful outcomes.

induced by faulty systems that set people up to fail" ${ }^{4}$ Medicine needs to understand the complexity of effective medical team training and focus research to address this challenge. Much work is needed to build an effective team training programme in medicine. Research needs to be conducted to identify the team topics and specific team skills for the medical profession. When this is complete, performance standards must be identified to create performance improvement measurements. This work must then be designed into a curriculum that supports integration of team training with technical performance. Finally, performance measurements must be conducted to identify the change in outcomes this training and simulation are effecting. This footprint for training must cross cultural boundaries and be part of an environment that is supported by the senior healthcare leadership. The primary similarity to aviation is that medicine also should no longer wait.

Competing interests: none declared

\section{REFERENCES}

1 Hackman RJ. Teams, leaders, and organizations: new directions for creworiented flight training. In: Wiener E, Kanki B, Helmreich R, eds. Cockpit resource management. San Diego, CA: Academic Press, 1993:47-70.

2 Johnston $\mathbf{N}$. Intergrating human factors training into ab initio airline pilot curricula. ICAO J 1993:48:14-17.

3 Diehl AE. Cockpit decision making. FAA Aviation Saf J 1991;1:14-16.

4 Kohn L, Corrigan J, Donaldson M, eds. To err is human: building a safer health system. Washington, DC: National Academy Press, 2000:146.

5 The President's Advisory Commission on Consumer Protection and Quility in the Health care Industry. Quality first: better health care for all Americans. Final report, Washington, DC, 1998:186.

6 Salas $E$, et al. Team training in the skies: does crew resource management (CRM) training work? Hum Factors 2001;43:641-74.

7 Fulginiti VA. The right issue at the right time. In: Holmes DE, Osterweis $M$, eds. Catalysts in interdisciplinary education: innovation by academic health centers. Washington DC: Association of Academic Health Centers, 1999.

8 Air Accidents Investigation Branch. Aircraft Accident Report 4/90: Report on the Accident to Boeing 737-400, OBME near Kegworth Leicestershire on Jan, 8, 1989. London: Department for Transport. Available at: http:// www.dft.gov.uk/stellent/groups/dft_avsafety/documents/page/ dft_avsafety_502831.hcsp.

9 Cardosi KM, Huntley MS. Cockpit and cabin crew coordination. DOT/FAA report No. DOT-TSC-FAA-87-4. Washington DC: US Department of Transportation (NTIS No. DOT/FAA/FS-88/1), 1988.

10 Brindle M, Mainiero LA. Managing power through lateral networking. Westport, CT: Quorum Books, 2000.

11 Cooper GE, White MD, Lauber JK, eds. Resource management on the flightdeck: proceedings of a NASA/industry workshop (NASA CP -2120). Moffett Field, CA: NASA-Ames Research Center, 1980.

12 Helmreich RL, Foushee HC. Why crew resource management? In: Wiener $E_{\text {, }}$ Kanke B, Helmreich R, eds. Cockpit resource management. San Diego, CA: Academic Press, 1993: 1-45.

13 Hamman W, Seamster T, Smith K, Lofaro R. The LOE Worksheet developed to provide clear structure to the assessment of both CRM and technical crew performance. ATA Conference 1993.

14 Bernard GR, Sopko G, Cerra F, et al. Pulmonary artery catheterization and clinical outcomes: National Heart, Lung, and Blood Institute and Food and Drug Administration Workshop Report. Consensus Statement. JAMA 2000;283:2568-2

15 Iberti TJ, Daily EK, Leibowitz AB, et al. Assessment of critical care nurses' knowledge of the pulmonary artery catheter. The Pulmonary Artery Cathete Study Group. Crit Care Med 1994;22:1674-8.

16 Iberti TJ, Fischer EP, Leibowitz AB, et al. A multicenter study of physicians' knowledge of the pulmonary artery catheter. Pulmonary Artery Catheter Study Group. JAMA 1990;264:2928-32.

17 Issenberg SB, McGaghie WC, Hart IR, et al. Simulation technology for health care professional skills training and assessment. JAMA 1999;282:861-6.

18 Derossis AM, Fried GM, Abrahamowicz M, et al. Development of a model for training and evaluation of laparoscopic skills. Am J Surg 1998;175:482-7.

19 Colluccio M, McGuire P. Collaborative practice: Becoming a reality through primary nursing. Nurs Admin Q 1983;7:59-63. 